\title{
PENGGUNAAN INFORMASI FINANSIAL DALAM MENGUKUR KINERJA ORGANISASI SEKTOR PUBLIK (STUDI PADA PUSKESMAS BAHU)
}

\author{
Brayel Topan Tambariki ${ }^{1}$, Herman Karamoy $^{2,}$ Steven J.Tangkuman ${ }^{3}$ \\ 1,2,3 Jurusan Akuntansi, Fakultas Ekonomi dan Bisnis, Universitas Sam Ratulangi, Jl. Kampus Bahu, Manado, \\ 95115, Indonesia
}

E-mail : brayeltopantambariki@gmail.com

\begin{abstract}
To succeed national development there are many aspects that must be considered. One of the most influential elements in national development is the budgetary. Budgetary issue is an important aspect, because it is one of the most vulnerable to fraud. Therefore, supervision of budget management should be held. In budgetary management, budget must fulfill three aspect of value for money, which are effectiveness, efficiency and economics. The State of Indonesia has many public sector organizations in various sectors. One of them is the organization in the health sector. Public sector organizations in the health sector are also important public sector organizations in national development, because they involve the interests of people's lives. In addition health is also one of the indicators in national development. Therefore, budget management in public sector organizations such as Puskesmas should be monitored for its performance, whether it is efficient, effective and economical. The purpose of this study is to determine the performance of Puskesmas Bahu based on the use of financial. This study used descriptive qualitative method. The results showed that financial information by measuring the level of economic, the level of efficiency and the level of effectiveness performance at the Puskesmas Bahu period 2014-2016 already fulfill the the aspect of value for money, which economical, efficient and effective.

Keywords : Performance Measurement, Value For Money, Economic, Efficiency, Effectiveness
\end{abstract}

\section{PENDAHULUAN}

Di era globalisasi adalah merupakan kesempatan untuk merubah pemikiran tentang pembangunan, untuk lebih maju dan merata secara keseluruhan bangsa dan negara. Dalam menyukseskan pembangunan nasional peran anggaran sangat penting dan mempunyai kedudukan yang sangat strategis dalam pembangunan nasional. Dalam hal ini penggunaan anggaran yang salah dapat membawa dampak yang kurang baik bagi kemajuan pembangunan nasional, untuk itu kita semua harus mengawasi nya terutama pihak yang bertanggungjawab untuk hal itu. Pemerintah harus mengevaluasi penggunaan tersebut agar anggaran yang di gunakan tidak di pergunakan dengan salah dan ujungnya menyebabkan kerugian kepada banyak pihak.

Berbicara tentang serapan anggaran, penyerapan anggaran adalah ukuran yang di pakai untuk standar. Semakin banyak anggaran yang terserap maka akan semakin baik, tapi pertanyaan nya adalah apakah anggaran yang terserap itu betul-betul bermanfaat dan untuk tujuan-tujuan yang sesuai dengan visi atau target dari pelayanan yang di inginkan untuk di capai atau anggaran hanya akan di gunakan untuk kepentingan diri sendiri.

Untuk itu pemerintah harus mengukur kinerja dari organisasi-organisasi yang bergerak di bagian sektor publik agar dapat mengetahui sejauh mana penggunaan anggaran tersebut, sejauh mana serapan anggaran yang terlaksana agar tujuan-tujuan pembangunan nasional bisa di raih. Dalam sektor kesehatan juga sangat penting dalam menyukseskan 
pembangunan nasional, untuk itu penggunaan dana dalam sektor ini cukup besar dan sangat kurang baik bila pengawasan kinerja di sektor ini tidak di ukur. Untuk itu proses pembangunan di bidang kesehatan perlu untuk di ukur agar penggunaan anggaran bisa di ketahui dengan harapan dapat membantu pembangunan nasional secara umum.

Puskesmas dalah garda terdepan dalam menangani kesehatan masyarakat baik itu di daerah perkotaan bahkan sampai daerah pedesaan, untuk mengoptimalkan pelayanan kepada masyarakat, puskesmas sebagai ujung tombak bagian kesehatan harus memberikan pelayanan yang baik agar setiap masyarakat merasa puas dan untuk menunjang pelayanan puskesmas sangat membutuhkan anggaran.

Meskipun pusat kesehatan masyarakat (Puskesmas) bergerak dalam pelayanan yang umum yaitu tidak terfokus pada tujuan untuk memperoleh keuntungan tetapi tetap harus mengolah anggaran dengan sebaik mungkin. Dalam organisasi publik, salah satunya adalah puskesmas, keuangannya harus baik antara lain transparan dan akuntabel agar anggaran tidak di salah gunakan dan kinerja dari pelaksanaan harus dapat dilaporkan dan di pertanggungjawabkan bagi pemerintah dan DPR yang mewakili masyarakat. (Iswahyudi Aries,2016:151-166)

Adapun tujuan yang ingin di capai dalam penelitian ini adalah untuk mengetahui kinerja puskesmas bahu berdasarkan penggunaan informasi finansial dengan mengukur tingkat ekonomis, tingkat efisiensi dan tingkat efekivitas.

\section{TINJAUAN PUSTAKA}

\subsection{Akuntansi Pemerintahan}

Halim (2013 : 1) menyatakan bahwa akuntansi keuangan (pemerintahan) daerah di Indonesia merupakan salah satu bidang dalam akuntansi sektor publik yang mendapat perhatian besar dari berbagai pihak semenjak reformasi tahun 1998. Dan menurut Sujarweni (2015 : 18) menjelaskan bahwa akuntansi pemerintahan adalah akuntansi yang bersangkutan dengan bidang keuangan negara, dari anggaran sampai dengan pelaksanaan dan pelaporannya, termasuk segala pengaruh yang ditimbulkannya.

\subsection{Akuntansi Sektor Publik}

Mardiasmo (2009 : 14) menyatakan akuntansi sektor publik terkait dengan tiga hal pokok, yaitu penyediaan informasi, pengendalian manajemen, dan akuntabilitas. Akuntansi sektor publik merupakan alat informasi baik bagi pemerintah sebagai manajemen maupun alat informasi bagi publik.

\subsection{Kinerja}

Kinerja adalah capaian kerja atau hasil yang telah di capai dalam pelaksanaan kegiatan. Dan juga menurut (I Gusti Agung Rai,2008:41) kinerja adalah cara perseorangan atau kelompok dari suatu organisasi menyelesaikan suatu pekerjaan atau tugas.

\subsection{Organisasi}

Menurut Ismainar (2015:1) organisasi adalah wadah untuk orang bersatu dan bekerja sama, bahu membahu, yang berpikiran sehat yang di rencanakan dengan baik, terorganisasi, terkendali, terpimpin untuk menjalankan sarana dan prasarana juga sumber daya yang ada demi tercapainya tujuan organisasi sedang kan sektor publik menurut (Mahsun,2006:7) adalah segalah sesuatu yang bersangkut paut dengan kepentingan umum. Dan di bayar menggunakan pajak yang tertulus dalam UU. Bila di gabungkan, organisasi sektor publik yakni tidak hanya organisasi sosial yang tidak mencari laba tapi lebih kepada penyediaan untuk kepentingan umum atau publik. Yaitu publik yang telah di bayar melalui pajak yang di atur dengan hukum yang berlaku (Mahsun,2006:14)

\subsection{Fungsi Puskesmas}

Menurut Permenkes RI No 39 Tahun 2016 halaman 44 menyatakan fungsi puskesmas adalah sebagai berikut : 
1.Sebagai pusat penggerak pembangunan berwawasan kesehatan.

a. Berupa mengerakan lintas sektor dan dunia usaha di wilayah kinerja agar menyelenggarakan pembangunan yang berwawasan kesehatan

b. Aktif membantu dan melaporkan dampak kesehatan dari penyelengaraan setiap program pembangunan di wilayah kerjanya.

c. Mengutamakan pemeliharaan kesehatan dan pencegahan penyakit tanpa mengabaikan penyembuhan dan pemulihan.

2. Pusat pemberdayaan masyarakat

Berupa agar perorangan, terutama pemuka masyarakat keluarga dan masyarakat.

a. Memiliki kesadaran, kemauan, dan kemampuan melayani diri sendiri dan masyarakat untuk hidup sehat.

b. Berperan aktif dalam memperjuangkan kepentingan kesehatan, termasuk pembiayaan.

c. Ikut menetapkan, menyelenggarakan, dan membantu pelaksanaan program kesehatan.

3. Pusat pelayanan kesehatan strata pertama

Menyelenggarakan pelayan kesehatan tingkat pertama secara menyeluruh, terpadu dan berkesinambungan.

\subsection{Elemen Value For Money dan Cara Pengukuran}

Value for money menurut Nordiawan $(2010: 161,162)$ yaitu sesuatu yang dapat memberikan petunjuk atau keterangan mengenai penggunaan anggaran yang di belanjakan untuk tujuan tertentu bagi masyarakat. Cara atau konsep mengelola keuangan organisasi sektor publik yaitu :
a. Ekonomis
b .Efesiensi
c. Efektivitas

1. Tingkat Ekonomis adalah Realisasi Pengeluaran di kali seratus persen di bagi anggaran pengeluaran

Kriteria Tingkat Ekonomis adalah :

a. Jika diperoleh nilai kurang dari seratus persen berarti Ekonomis.

b. Jika diperoleh nilai sama seratus persen berarti Ekonomis berimbang.

c. Jika diperoleh nilai lebih dari seratus persen berarti tidak Ekonomis

2. Tingkat Efesiensi adalah Realisasi Biaya Untuk Memperoleh Pendapatan di Kali Seratus di Bagi Realisasi Pendapatan

Kriteria Tingkat Efesiensi adalah :

a. Jika diperoleh nilai kurang dari seratus persen berarti Efisien

b. Jika diperoleh nilai sama dengan seratus persen berarti Efesien berimbang

c. Jika diperoleh nilai lebih dari seratus berarti tidak efesiensi

3. Tingkat Efektivitas adalah Realisasi Pendapatan di Kali seratus di Bagi Anggaran Pendapatan

Kriteria Tingkat Efektivitas adalah
a. Jika diperoleh nilai kurang dari seratus persen berarti tidak Efektif
b. Jika diperoleh nilai sama dengan seratus persen berarti Efektif berimbang
c. Jika diperoleh nilai lebih dari seratus persen berarti Efektif

\section{METODE PENELITIAN}

\subsection{Jenis dan sumber data}

Penelitian ini menggunakan metode studi kasus pada subjek yang akan diteliti dengan pendekatan deskriptif kualititatif. Peneliti mengumpulkan data secara lengkap dengan berbagai prosedur pengumpulan data berdasarkan waktu yang telah ditetapkan. 


\subsection{Teknik Pengumpulan Data}

Teknik pengumpulan data yaitu dengan cara melihat informasi finansial laporan keuangan puskesmas bahu tahun 2014-2016 yang di butuhkan, dan mengambil data gambaran umum puskesmas bahu.

\subsection{Interprestasi data}

Data diolah dan diterjemahkan menggunakan value for money sebagai alat ukur. Penelitian ini menggunakan Microsoft Excel 2016 sebagai alat bantu

\section{HASIL ANALISIS DAN PEMBAHASAN}

\subsection{Hasil analisis Hasil Penelitian}

Berikut adalah hasil penelitian yang telah dilakukan di Puskesmas Bahu, Dalam menghitung anggaran puskesmas, menggunakan 3 cara teknik pengukuran Value For Money, yaitu :

\section{Tingkat Ekonomi}

Perhitungan :

$$
\text { Tahun } 2014 \frac{637.863 .812}{980.080 .000} \quad \text { X } \quad 100 \%=65,09 \%
$$

$\mathrm{X}<100 \%$ Maka pengelolaan pengeluaran puskesmas pada Tahun 2014 adalah Ekonomis

$$
\text { Tahun } 2015 \frac{982.161 .803}{1.026 .000 .000} \quad \mathrm{X} \quad 100 \%=95,73 \%
$$

$\mathrm{X}<100 \%$, Maka pengelolaan pengeluaran puskesmas pada Tahun 2015 adalah Ekonomis.

$$
\text { Tahun } 2016 \frac{1.110 .400 .000}{1.196 .424 .397} \quad \mathrm{X} \quad 100 \%=92,80 \%
$$

$\mathrm{X}<100 \%$, Maka pengelolaan pengeluaran puskesmas pada Tahun 2015 adalah Ekonomis.

\section{Tingkat Efisiensi}

Perhitungan :

$$
\text { Tahun } 2014 \frac{94.026 .856}{733.330 .397} \quad \mathrm{X} \quad 100 \%=12,83 \%
$$

$\mathrm{X}<100 \%$ Maka pengelolaan pengeluaran puskesmas pada Tahun 2014 adalah Efisien.

$$
\text { Tahun } 2015 \frac{80.090 .431 .43}{1.159 .797 .597} \quad \mathrm{X} \quad 100 \%=06,91 \%
$$

$\mathrm{X}<100 \%$ Maka pengelolaan pengeluaran puskesmas pada Tahun 2015 adalah Efisien.

$$
\text { Tahun } 2016 \frac{64.842 .373 .26}{1.196 .242 .397} \quad \mathrm{X} \quad 100 \%=05,42 \%
$$

$\mathrm{X}<100 \%$ Maka pengelolaan pengeluaran puskesmas pada Tahun 2016 adalah Efisien.

\section{Tingkat Efektfitas :}

Perhitungan :

Tahun $2014 \frac{800.310 .000}{733.330 .397} \quad \mathrm{X} \quad 100 \%=91,63 \%$

X $<100 \%$, maka pengelolaan pendapatan puskesmas pada Tahun 2014 tidak Efektif

Tahun $2015 \frac{1.040 .000 .000}{1.159 .797 .597} \quad \mathrm{X} \quad 100 \%=89,68 \%$

X $<100 \%$, maka pengelolaan pendapatan puskesmas pada Tahun 2014 tidak Efektif. 
Tahun $2016 \frac{1.150 .000 .000}{1.196 .424 .397} \quad \mathrm{X} \quad 100 \%=96,71 \%$

X $<100 \%$, maka pengelolaan pendapatan puskesmas pada Tahun 2014 tidak Efektif.

\subsection{Pembahasan}

Pengelolaan Anggaran Puskesmas

Tingkat Ekonomi

Tabel 1 Tingkat Ekonomi Pengelolaan Anggaran

\begin{tabular}{|c|c|c|}
\hline TAHUN & \% & TINGKAT EKONOMI \\
\hline 2014 & $65,09 \%$ & EKONOMIS \\
\hline 2015 & $95,73 \%$ & EKONOMIS \\
\hline 2016 & $92,80 \%$ & EKONOMIS \\
\hline
\end{tabular}

Sumber :Data yang diolah dengan Microsof Excel 2016

1. Berdasarkan data yang diolah dari Laporan Realisasi Dana pada Puskesmas Bahu, pada Tahun 2014, tingkat ekonomis di puskesmas Bahu adalah Ekonomis (65,09\%), yang berarti Puskesmas Bahu bisa menghindari anggaran pengeluaran yang boros, tidak perlu dan tidak produktif.

2. Berdasarkan data yang diolah dari Laporan Realisasi Dana pada Puskesmas Bahu, pada Tahun 2015, tingkat ekonomis di puskesmas Bahu adalah Ekonomis $(95,73 \%)$ dan yang berarti Puskesmas Bahu dapat menghindari pengeluaran yang boros dan tidak produktif.

3. Berdasarkan data yang diolah dari Laporan Realisasi Dana pada Puskesmas Bahu, pada Tahun 2016, tingkat ekonomis di puskesmas Bahu adalah Ekonomis $(92,80 \%)$, yang berarti Puskesmas Bahu bisa menghindari anggaran pengeluaran yang boros, tidak perlu dan tidak produktif.

\section{Tingkat Efisiensi}

Tabel 2 Tingkat Efisiensi Pengelolaan Anggaran

\begin{tabular}{|c|c|c|}
\hline TAHUN & \% & TINGKAT EFISIENSI \\
\hline 2014 & $12,83 \%$ & EFISIEN \\
\hline 2015 & $06,91 \%$ & EFISIEN \\
\hline 2016 & $05,42 \%$ & EFISIEN \\
\hline
\end{tabular}

Sumber :Data yang diolah dengan Microsof Excel

1. Pada Tahun 2014, tingkat efisiensi di Puskesmas Bahu adalah Efisien (12,83\%), realisasi biaya untuk memperoleh pendapatan, dalam hal ini adalah subsidi dari pemerintah untuk puskesmas, sesuai atau lebih kecil dari realisasi pendapatan puskesmas. Berbeda dengan sistem yang diterapkan pada puskesmas di tahun-tahun sebelumnya, saat ini realisasi pendapatan tidak lagi didapat dari masyarakat yang berobat ke puskesmas, melainkan semuanya bersumber dari subsidi pemerintah daerah kepada puskesmas

2. Pada Tahun 2015, tingkat efisiensi di Puskesmas Bahu adalah Efisien (06,91\%), realisasi biaya untuk memperoleh pendapatan, dalam hal ini adalah subsidi dari pemerintah untuk puskesmas, sesuai atau lebih kecil dari realisasi pendapatan puskesmas.

3. Pada Tahun 2016, tingkat efisiensi di Puskesmas Bahu adalah Efisien $(05,42 \%)$, realisasi biaya untuk memperoleh pendapatan, dalam hal ini adalah subsidi dari pemerintah untuk puskesmas, sesuai atau lebih kecil dari realisasi pendapatan puskesmas. 
Tingkat Efektivitas

Tabel 3 Tingkat Efektivitas Pengelolaan Anggaran

\begin{tabular}{|c|c|c|}
\hline TAHUN & \% & TINGKAT EFEKTIVITAS \\
\hline 2014 & $91,63 \%$ & TIDAK EFEKTIF \\
\hline 2015 & $89,68 \%$ & TIDAK EFEKTIF \\
\hline 2016 & $96,71 \%$ & TIDAK EFEKTIF \\
\hline
\end{tabular}

Sumber :Data yang diolah dengan Microsof Excel

1. Pada Tahun 2014, tingkat efektivitas di Puskesmas Bahu adalah tidak efektif ( , yang berarti tingkat pencapaian hasil adalah tidak efektif. Berbeda dengan tahun-tahun sebelumnya, dikarenakan saat ini puskesmas tidak lagi memperoleh pendapatan dari masyarakat, maka tidak ada target pendapatan yang harus diterima puskesmas setiap tahunnnya. Satu-satunya sumber pendapatan puskesmas adalah dari subsidi pemerintah, sehingga subsidi yang diberikan pemerintah harus dihabiskan pada tahun tersebut. Karena setiap tahunnya anggaran dari pemerintah harus terealisasi sesuai dengan anggaran yang diterima, menyebabkan setiap tahunnya hasil perhitungan tingkat efektivitas adalah tidak efektif,

2. Pada Tahun 2015, tingkat efektivitas di Puskesmas Bahu adalah tidak efektif ( yang berarti tingkat pencapaian hasil tidak efektif.

3. Pada Tahun 2016, tingkat efektivitas di Puskesmas Bahu adalah tidak efektif ( yang berarti tingkat pencapaian hasil adalah tidak efektif.

\section{KESIMPULAN DAN SARAN}

5.1. Kesimpulan

berikut :

Adapun hasil dari penelitian yang dilakukan dan bisa di tarik kesimpulan sebagai

1. Tingkat Ekonomis

Tingkat Ekonomis Puskesmas Bahu sudah dapat dikatakan ekonomis atau baik karena Tahun 2014 dengan (65,09\%), 2015 dan 2016 dengan (95,73\%) dan $(92,80 \%)$ adalah Ekonomis karena Puskesmas Bahu dapat menghindari pengeluaran yang boros seperti biaya fotokopi, pembelian printer, alat-alat medis dan ATK dan tidak produktif dan dapat menggunakan anggaran dengan baik.

2. Tingkat Efisiensi

Tingkat Efisien Puskesmas Bahu dapat di katakan baik karan Tahun 2014 dan 2015 dan 2016 adalah Efisien karena realisasi biaya untuk memperoleh pendapatan, dalam hal ini adalah subsidi pemerintah dari pemerintah untuk puskesmas, sesuai atau lebih kecil dari realisasi biaya untuk memperoleh pendapatan puskesmas.

3. Tingkat Efektivitas

Tingkat Efektivitas Puskesmas Bahu adalah tidak Efektif karena di Puskesmas Bahu pencapaian hasil sesuai denga anggaran pendapatan dan realisasi tidak lebih besar dan dari penerimaan yang di terima atau realisasi angaran Puskesmas Bahu yang ingin dicapai.

\subsection{Saran}

Hasil penelitian dan pembahasan diatas maka penulis mengusulkan beberapa saran sebagai berikut:

1. Kepada pengelola anggaran agar kinerja puskesmas yang diukur dari informasi finansial menggunakan value for money yang sudah dicapai dapat dipertahankan di tahun-tahun berikutnya. Serta tetap melakukan pengawasan dalam pengelolaan anggaran yang ada di puskesmas Bahu. 
2. Kepada semua pengawai Puskesmas Bahu, mulai dari pimpinan, medis, paramedis, dan non paramedis untuk terus menjaga kinerja Puskesmas Bahu dalam menangani dan melayani masyarakat yang ada di kelurahan Bahu bahkan sekitarnya. Meningkatnya kesadaran masyarakat akan hidup sehat akan membantu pemerintah dalam mensejahterakan rakyat.

3. Kepada Puskesmas Bahu untuk memberikan penyuluhan kepada masyarakat agar kesadaran dan kepedulian masyarakat tentang hidup sehat meningkat, yang nantinaya akan berimbas kepada masyarakat yang sehat dan sejahtera.

4. Kepada pemerintah dalam hal ini dinas kesehatan untuk lebih meningkatkan kerjasama yang baik maka semakin meningkatkan pelayanan yang ada di puskesmas.

5. Kepada peneliti untuk tidak berhenti dalam melakukan perbaikan agar penelitan selanjutnya bisa lebih baik lagi.

\section{DAFTAR PUSTAKA}

Ardila Isna, Ayu Aninda Putri, 2015. Analisis Kinerja Keuangan Dengan Pendekatan Value For Money Pada Pengadilan Negeri Tebing Tinggi. JURNAL Riset Akuntansi Dan Bisnis Volume 15 No.1

Deddi Nordiawan, Ayuningtyas hertianti. 2010. Akuntansi Sektor Publik. Salemba Empat. Jakarta

Halim, abdul. 2013. Akuntansi Keuangan Daerah. Edisi Revisi. Salemba Empat. Jakarta

Ismainar, Hetty. 2015. Manajemen Unit Kerja: Untuk Perekam Medis dan Informatika Kesehatan dan Ilmu Kesehatan Masyarakat Keperawatan dan Kebidanan. Yogyakarta. Deepublish

Iswahyudi Aries, Iwan Triyuwonob, M. Achsinc, 2016. Hubungan Pemahaman Akuntabilitas Transparansi, Partisipasi, Value For Money dan Good Governance. Jurnal Ilmiah Akuntansi Vol. 1, Vol2, Hal: 151-166

Mahsun. Muhamad 2006. Pengukuran Kinerja Sektor Publik, Yogyakarta : BPFE

Mardiasmo. 2009. Akuntansi sektor Publik, Yogyakarta: ANDI

Republik Indonesia. 2004. Keputusan Menteri Kesehatan tentang Kebijakan Dasar Pusat Kesehatan Masyarakat. Sekertariat Negara. Jakarta

Republik Indonesia. 1999. PP No.22 Tahun 1999 tentang Pemerintah Dearah. Sekertariat Negara. Jakarta.

Republik Indonesia. 1999. PP No.25 Tahun 1999 tentang Perimbangan Keuangan Antara Pemerintah Pusat Dearah. Sekertariat Negara. Jakarta.

Rai,2008. Audit Kinerja Pada Sektor Publik. Salemba Empat. Jakarta

Sujarwani Wiratna. 2015. Akuntansi Sektor Publik. Pustaka Baru Press. Yogyakarta 